\title{
Combined Approach Excision of a Giant Frontal Sinus Osteoma: Case Report with Literature Review
}

\author{
Monil Parsana, Rajesh Vishwakarma, Abhishek Gugliani* and Kalpesh Patel \\ Department of ENT, BJ Medical College, India \\ *Corresponding author: Abhishek Gugliani, Department of ENT, BJ Medical College, India
}

\begin{abstract}
Osteomas are benign tumors of osteogenic origin. They are common in the para nasal sinuses with frontal sinus being the most commonly involved. They are extremely slow growing and hence are usually asymptomatic and discovered incidentally. However, large tumors can present with compressive symptoms and sinusitis due to blockage of the natural drainage of the sinus. Headache is the commonest symptom at presentation. Complete surgical excision is the treatment of choice. We present one such case of a giant frontal sinus osteoma that presented to us with the complaints of frontal headache and diplopia. The technique of resection along with the review of literature is presented.
\end{abstract}

Keywords: Frontal Sinus; osteoma; surgery

\section{Introduction}

Osteomas are slow growing, benign tumors of osteogenic origin. They are common in the paranasal sinuses, often found in the frontal sinus and the frontal recess region [1]. The incidence of osteomas is $0.014 \%-0.43 \%$ in the general population [2]. Most of them remain asymptomatic and are often diagnosed incidentally however, signs and symptoms depend upon the location of the tumor, its size and extension to adjacent structures [3]. We report a case of a large front-ethmoid osteoma which presented with a facial deformity. A combination of external and endoscopic surgery was used to confirm the complete removal and check the patency of the sinus drainage.

\section{Case Report}

A 48-year-old female presented to us with complaints of right sided frontal headache, swelling on right side forehead and diplopia since last 2 months. The pain was dull aching in nature, continuous, without any diurnal variation and only partially relieved by over the counter analgesics. There was no history of trauma or significant medical events in past. On examination, right side inferior displacement of eye was noticed with tenderness over right frontal and ethmoidal region. A diagnostic nasal endoscopy did not reveal any anomaly except for thick mucoid secretions in the region of frontal recess on the right side. Visual acuity was normal. Computed tomography (CT) paranasal sinuses revealed a large osteoma in the right side frontoethmoidal region along with retained secretions in the frontal sinus (Figure 1). The lesion was seen bulging in the orbit and sub frontal region without any intracranial involvement. Due to the large size of tumor, it was decided to go for an open approach under general anaesthesia for excision of the tumor. A Lynch-Howarth incision was made in the right front-ethmoidal region for proper exposure (Figures 2 \& 3). Simultaneous nasal endoscopy was performed to clear the frontal recess and to ensure proper drainage of the sinus. The tumor was removed enbloc and was about $3 \times 3 \times 2 \mathrm{~cm}$ in dimensions (Figure 4). Right side nasal packing was done. The post-operative period was uneventful, and the pack was removed on day 1. Histopathological examination confirmed it as an osteoma. The patient was regularly followed up for about 2 years and did not have any complaints. 


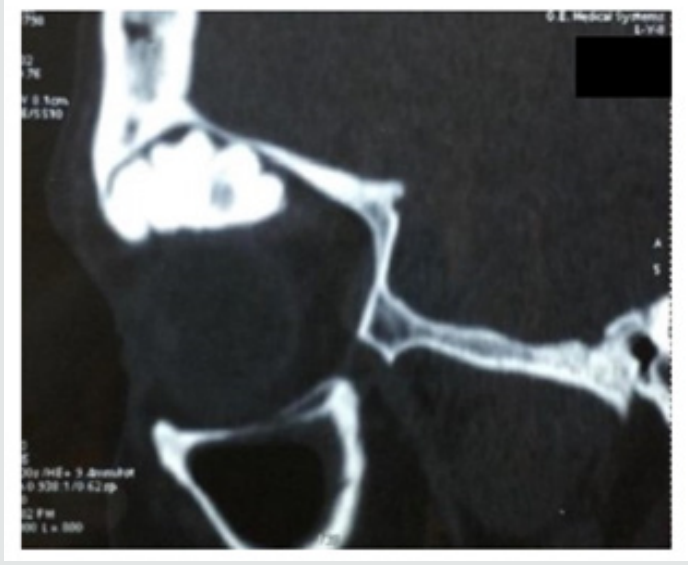

Figure 1: Sagittal section showing Right frontal sinus osteoma.

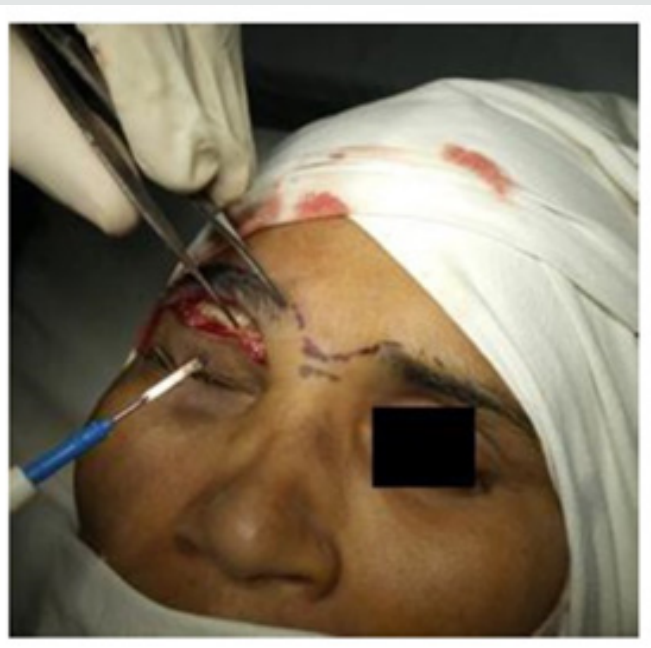

Figure 2: External approach for exposure of the tumor.

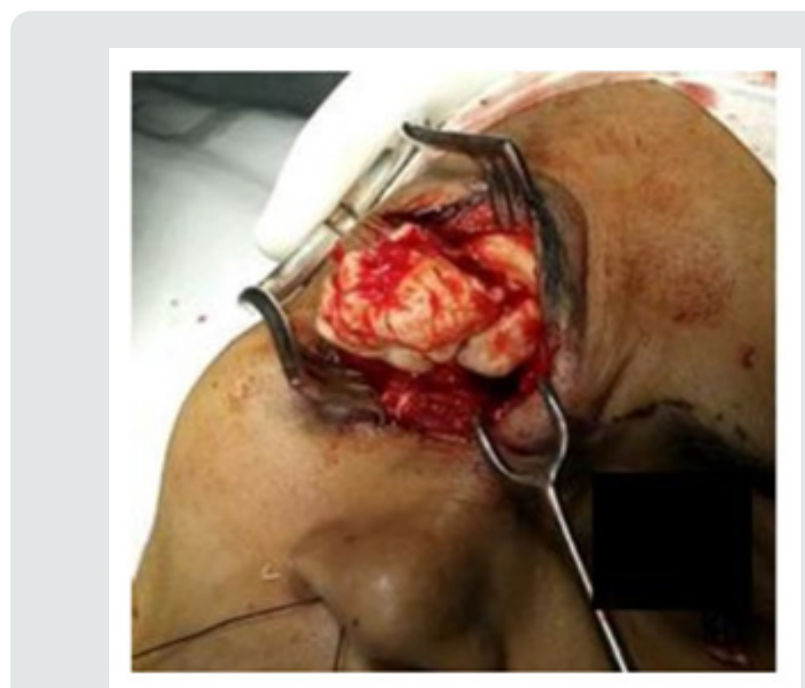

Figure 3: Tumor exposed.

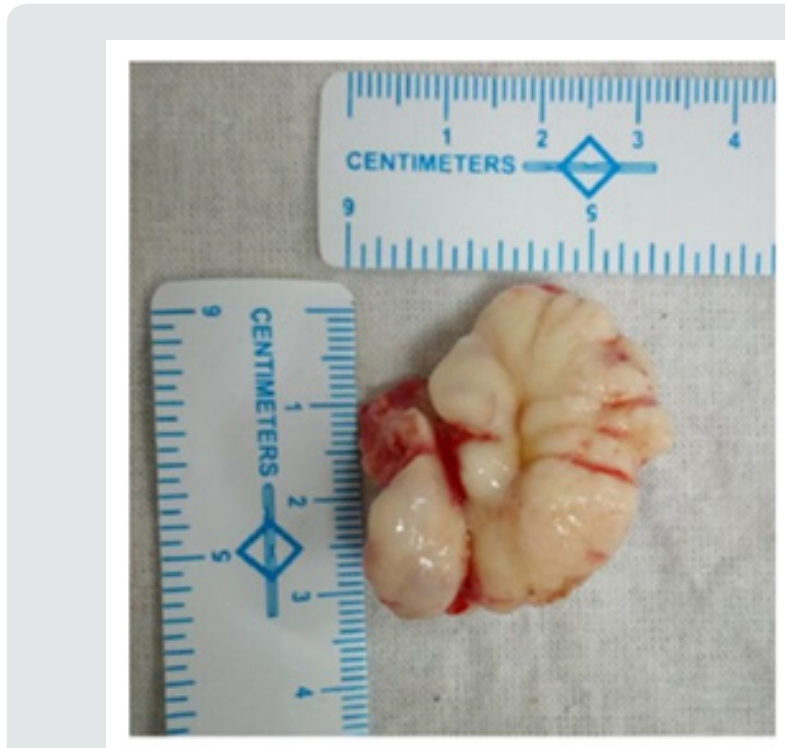

Figure 4: Specimen removed en-bloc

\section{Discussion}

Osteomas are osteogenic tumor of paranasal sinuses. They are benign but locally invasive. They occur at any age but are common in the third and fourth decades of life [4]. These are slow growing tumors with a reported mean growth rate of $1.61 \mathrm{~mm} /$ year, ranging from 0.44 to $6.0 \mathrm{~mm} /$ year [5]. The exact etiology is not known, and various theories have been proposed, embryological, metaplastic, post traumatic or genetic [6]. Osteomas are usually asymptomatic, and the diagnosis is mostly incidental. However, large tumors can present with pressure symptoms with headache being the commonest of them all. Other symptoms include proptosis, diplopia, sinusitis, cosmetic disfigurement and rarely, neurological complications [7]. A CT scan is the imaging modality of choice for osteoma as it clearly demarcates the bony lesion and also helps to plan the surgery. Based on the size of tumor in relation to the frontal recess, its attachment and location in relation to a sagittal plane passing through the lamina papyracea, Chiu et al. have proposed a grading system of osteoma [8].

a) Grade I: Origin of osteoma posterior and inferior in frontal recess, location medial to the sagittal plane and anteroposterior (AP) diameter of tumor $<75 \%$ of that of the frontal sinus.

b) Grade II: Same as I with AP diameter $>75 \%$ of the frontal recess

c) Grade III: Origin anterior and/or superior in the frontal recess and the tumor extends lateral to the sagittal plane.

d) Grade IV: Osteoma fills the entire frontal sinus.

Surgical excision is the treatment of choice for symptomatic lesions [9]. Surgery can be via an open approach with an osteoplastic flap, via a Lynch-Howarth incision in the eyebrow, endoscopic approach or a combination. Our patient presented to us with complaints of headache, cosmetic disfigurement and diplopia. 
CT scan showed an osteoma of the fronto-ethmoidal region of the involved side. Due to the large size of the tumor (giant osteoma), a decision was made to go for a combined external and endoscopic excision for removal of the tumor. The advantage of an external approach is better visualization of the osteoma and less operative time. An endoscopic approach, on the other hand, offers better cosmesis and reduced post-op morbidity, however, it may not always be feasible in cases of very large osteomas [10]. Osteomas are not known for malignant transformation and the goal of surgery is to relieve the symptoms with re-establishment of the drainage of the sinus [2]. Thus, a conservative approach can be followed during surgery. Recurrences are usually not known after a complete resection.

\section{Conclusion}

Osteomas are benign osteogenic tumors commonly involving the frontal and ethmoidal paranasal sinus. They are slow growing, asymptomatic and more often than not, discovered incidentally. Only large symptomatic osteomas warrant a surgical excision. The route of surgery depends on the size of tumor, its relation to the neighboring structures and the experience of the surgeon. A combined approach offers the advantage of proper visualization of the tumor via the external route while achieving proper drainage of the frontal sinus through endoscopy.

\section{References}

1. Larrea Oyarbide N, Valmaseda Castellon E, Berini Aytes L, Gay Escoda C (2008) Osteomas of the craniofacial region. Review of 106 cases. J Oral Pathol Med 37: 38-42.

2. Secer HI, Gonul E, Izci Y (2008) Surgical management and outcome of large orbito cranial osteomas. J Neurosurg 109: 472-477.

3. Cheng KJ, Wang SQ Lin L (2013) Giant osteomas of the ethmoid and frontal sinuses: clinical characteristics and review of the literature. Oncol Lett 5(5): 1724-1730.

4. Nielsen GP, Rosenberg AE (2007) Update on bone forming tumors of the head and neck. Head Neck Pathol 1: 87-93.

5. Koivunen P, lopponen H, Fors AP, Jokinen K (1997) The growth rate of osteomas of the paranasal sinuses. Clin Otolayngol Allied Sci 22(2): 111114.

6. Boffano P, Roccia F, Campisi P (2012) Review of 43 osteomas of the craniomaxillofacial region. J Oral Maxillofac Surg 70: 1093-1095.

7. Watelet JB, Van Cauwenberge P (1999) Applied anatomy and physiology of the nose and paranasal sinuses. Allergy 54(Supp 57): 14-25.

8. Chiu AG, Schipor I, Cohen NA, Kennedy DW, Palmer JN (2005) Surgical decisions in the management of frontal sinus osteomas. Am J Rhinol 19: 191-197.

9. Eller R, Sillers M (2006) Common fibro-osseous lesions of the paranasal sinuses. Otolaryngol Clin North Am 39: 585-600.

10. Bignami M, Dallan I, Terranova P, Battaglia P, Miceli S et al (2007) Frontal sinus osteomas: the window of endonasal endoscopic approach. Rhinology 45: 315-320.
This work is licensed under Creative Commons Attribution 4.0 License

To Submit Your Article Click Here: Submit Article
DOI: $10.32474 /$ SJO.2019.03.000160

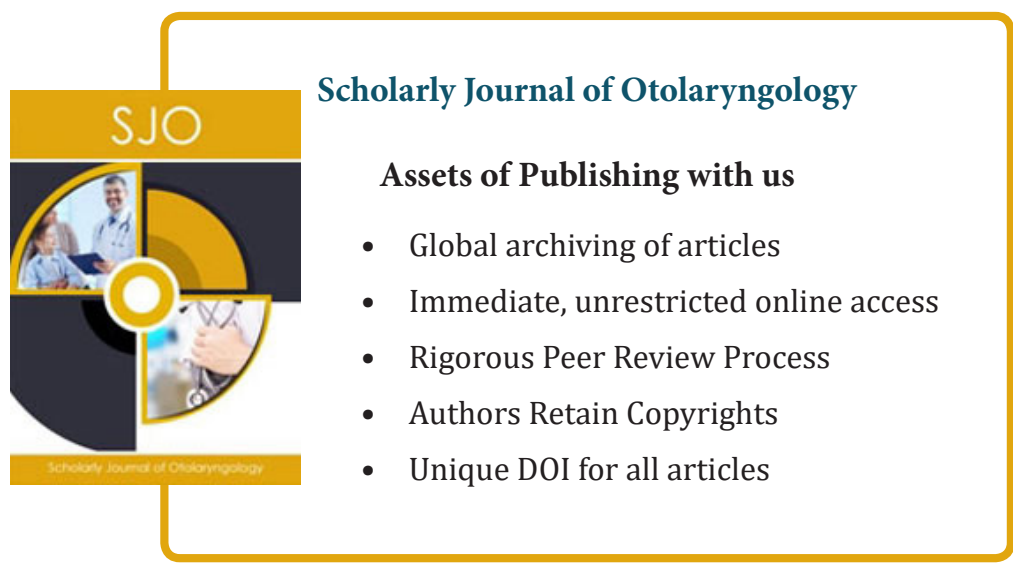

